\title{
Performance no aplicativo Tinder: a percepção das mulheres acerca das narrativas dos usuários homens na plataforma
}

Self-performance in Tinder application: the women's perception of the male users's narratives on the platform

\section{Rendimento de la aplicación de Tinder: percepsión de las mujeres sobre las narrativas de los usuários masculinos em la plataforma}

\begin{abstract}
Fernanda Angelo Costantino
Doutoranda do Programa de Pós-Graduação em Mídia e Cotidiano, da Universidade Federal Fluminense (UFF). Mestre pelo mesmo programa, com pesquisa acerca do aplicativo para dispositivos móveis Tinder. Graduada em Comunicação Social, com habilitação em Jornalismo, pela mesma universidade. Universidade Federal Fluminense - UFF/RJ - Brasil http://lattes.cnpq.br/9355682407876251
\end{abstract}

\begin{abstract}
Resumo: O trabalho busca discutir a performance de si no aplicativo Tinder, com foco principalmente no conceito de gerenciamento da impressão elaborado por Erwing Goffman (2002), e a partir de um recorte metodológico e teórico voltado para como as mulheres recebem as narrativas dos usuários homens no programa. Para a elaboração deste trabalho, foram analisados 100 perfis de usuários homens e realizadas entrevistas semiestruturadas com oito usuárias mulheres, a partir de uma perspectiva etnográfica.
\end{abstract}

Palavras-chave: Identidade. Performance. Gerenciamento da Impressão. Autenticidade. Tinder. 
Abstract: The paper aims to discuss self-performance in the app Tinder, focusing mainly on the concept of impression management by Erwing Goffman (2002), and from a methodological and theoretical perspective on how women receive the narratives of male users in the program. For the elaboration of this work, 100 profiles of male users were analyzed and semi-structured interviews were carried out with eight female users, from an ethnographic perspective.

Keywords: Identity. Performance. Impression Management. Authenticity. Tinder.

Resumen: El documento busca discutir el autoevaluación em la aplicación Tinder, centrándose principalmente em el concepto de gestión de impresión elaborado por Erwing Goffman (2002), y desde um enfoque metodológico y teórico centrado em como las mujeres reciben las narrativas de los usuários masculinos em el programa. Para la elaboración de este trabajo, se analizaron 100 perfiles de usuários masculinos y se realizaron entrevistas semiestructuradas com ocho usuárias, desde uma perspectiva etnográfica.

Palabras-clave: Identidad. Rendimiento. Gestión de impresión. Autenticidad. Tinder.

\section{Introdução}

Tinder é um aplicativo para dispositivos móveis, lançado no final de 2012 pela empresa norte-americana Match Group. Com 100 milhões de usuários no mundo todo e 10 milhões só no Brasil ${ }^{1}$, o Tinder tem como público-alvo aqueles que estão em busca de uma amizade ou relacionamento amoroso. Velocidade é uma das palavras-chave que define o programa. São sete minutos em média que os usuários permanecem no aplicativo durante as 11 vezes que o acessam por dia, interações que rendem uma média de 26 milhões de casais combinados todo dia pelo mundo. Para utilizar o Tinder, o usuário se inscreve a partir de sua conta no site de rede social Facebook e a plataforma cruza seus dados pessoais com sua localização geográfica. Após o cadastro, uma lista de possíveis pretendentes é exposta na interface do programa e o participante pode 
gostar ou não do perfil sugerido, com uma simples interação na tela: deslizando o perfil para a esquerda a opção é rejeitada, para a direita é aprovada (há também a opção de tocar a imagem de um coração ou um X para gostar ou não da opção). Os perfis são ordenados como numa pilha de cartas e só é possível analisar o próximo após avaliar o atual.

Quando a aprovação vem de ambos os lados, é exibida uma mensagem na tela avisando "It's a match!" ("Vocês combinam!", na tradução em português do aplicativo), e os usuários podem iniciar uma conversa. Só é permitido manter contato com aquele que também avaliou positivamente o seu perfil em troca. Cada perfil é composto por até seis fotos e uma descrição de, no máximo, 500 caracteres. Conseguir um match está entre os objetivos de quem utiliza o programa. Para tal, algumas estratégias, simbolismos e ferramentas são utilizados com a finalidade de tornar sua persona cada vez mais interessante aos olhos do outro. Se pensarmos no tempo médio de utilização, prender a atenção do público é uma das estratégias de gerenciar o contato e fazer com que seu perfil não passe despercebido entre os tantos que compõem a lista de possíveis pretendentes. Além disso, a performance no programa também é construída com o objetivo de gerar credibilidade e autenticidade para seu público.

A performance, muitas vezes, está ligada à tentativa de atender e prever os desejos do outro. Dessa maneira, a própria identidade pode ser construída a partir do olhar de fora; nas palavras de Slater: "em relação a estar de acordo com as expectativas transitórias do outro" (SLATER, 2002, p. 92). A maior parte dos perfis construídos no Tinder parece seguir essa lógica e são construídos de forma estratégica e com a finalidade de gerenciar a impressão que o outro terá de sua autoapresentação.

O que se pretende explorar neste trabalho, a partir de uma base teóricometodológica concentrada no conceito de gerenciamento da impressão de Goffman $(2002)^{2}$, é a forma como a impressão do outro interfere nesse processo de subjetivação, no ambiente mediado do Tinder. Na plataforma, os perfis são criados, em parte, em uma constante busca por se manter notável, interessante e mais merecedor da aprovação que o usuário a seguir. 
Regular a impressão que o outro terá de nós mesmos é uma das principais tarefas desempenhadas no cotidiano e, também, nas plataformas digitais. O gerenciamento da impressão (GOFFMAN, 2002) é parte intrínseca dos processos das dinâmicas de autoapresentação nas mídias digitais e em sites de redes sociais e de aplicativos sociais (POLIVANOV, 2014; RIBEIRO, FALCÃO E SILVA, 2010; CARRERA, 2012). O conceito diz respeito à forma como, quando na presença do outro, as ações e impressões causadas pelo indivíduo definirão a situação ali disposta, no sentido de que uma ação irá levar a uma resposta específica que se deseja receber. Em certas ocasiões, o indivíduo "agirá de maneira completamente calculada, expressando-se de determinada forma somente para dar aos outros o tipo de impressão que irá provavelmente levá-los a uma resposta específica que lhe interessa obter" (GOFFMAN, 2002, p. 15).

Goffman atenta ainda para a importância da primeira impressão em uma relação social. As interações são em grande medida baseadas em inferências, ou seja, confia-se que determinado indivíduo terá determinado comportamento porque é o que se espera dele (GOFFMAN, 2002). Da mesma forma que, a partir da projeção que se faz de si mesmo, espera-se um tratamento específico em troca. Novamente, se pensarmos nos perfís construídos na plataforma, as atenções estão voltadas ao que o outro acharia e sobre o que o outro se interessaria, de maneira que se espera em troca que seu próprio perfil seja aprovado.

Especificamente em relação aos meios online, Nancy Baym (2010), ao abordar as novas formas de conexões sociais em ambientes digitais de interação, afirma que algumas mídias podem oferecer um número insuficiente do que chama de pistas sociais, ou seja, informações importantes que identificam socialmente o outro e nos fazem sentir seguros em iniciar o contato. As pistas sociais são importantes também para o processo de gerenciamento da impressão, já que permitem a construção de um contexto no qual é possível gerenciar a performance desejada.

Baym argumenta que, muitas vezes, ocorre um processo denominado pela autora como "self-disclosure" (BAYM, 2010, p. 109), ou seja, o processo de expor aquilo que se acredita ser o "verdadeiro self". Tal processo seria uma forma de afirmar-se como um sujeito autêntico e de firmar mais facilmente conexões 
com pessoas com as quais não se possuía laços anteriores (SÁ, POLIVANOV; 2012, p. 580), novamente dentro do processo de gerenciamento da performance.

Porém, o processo de self-disclosure e de gerenciamento de tais pistas sociais não é feito discriminadamente. Há uma preocupação com as estratégias de autoapresentação, preocupação essa também ligada ao que Giddens chama de projeto reflexivo da construção da identidade (2002). De acordo com o autor, as narrativas de si aparecem de forma explícita, almejando obter uma coerência expressiva. Ainda segundo Giddens, na alta modernidade, a identidade é construída continuamente como um processo que sempre se renova, já que as narrativas pretendem se manter coerentes e, assim, são expostas a constantes revisões. No Tinder, por exemplo, ao se analisar a eficiência que seu próprio perfil possui em relação à obtenção de likes, os usuários realizam revisões, na expectativa de melhorar a experiência no programa - assunto que já foi tema de trabalhos anteriores (WARD, 2016).

Para atingir o objetivo principal desta pesquisa, ou seja, entender como são recebidas as performances de si na plataforma Tinder, a perspectiva abordada foi a partir da maneira como o público feminino recebe as narrativas de autoapresentação dos homens heterossexuais, possibilitando assim a análise das concordâncias e rupturas que tais narrativas sofrem ao longo do processo. Como metodologia escolhida, realizou-se um estudo de inspiração etnográfica, entendendo tais estudos como aqueles que não adotam a etnografia em si como metodologia, mas "que se utilizam de partes dos procedimentos etnográficos de pesquisa" e que podem "incorporar protocolos metodológicos e práticas de narrativa como histórias de vida, biografias ou documentos para compor a análise dos dados" (AMARAL, FRAGOSO E RECUERO, 2012, 168).

A primeira coleta de dados foi a partir da observação participante no aplicativo pelo período de quatro semanas, em outubro de 2017, por aproximadamente 20 minutos por dia e a partir do meu perfil pessoal do Facebook vinculado ao programa. $\mathrm{Na}$ descrição do perfil, explicitei realizar uma pesquisa e não interagi diretamente pelo aplicativo com outros usuários. Nos filtros disponibilizados pelo programa, foram escolhidas as opções entre 18 e 34 anos, faixa que corresponde ao grupo com maior número de usuários no programa (83\%), 
além da opção de interesse em homens a um raio de distância de até 160 km (o que corresponde ainda ao Estado do Rio de Janeiro, região onde foi feita a análise).

A etapa de observação participante foi realizada para a preparação da segunda etapa, de entrevistas, não se tratando de uma pesquisa quantitativa. De toda forma, vale destacar alguns dados extraídos nesta etapa, na qual foram analisados 100 perfis de homens residentes do Rio de Janeiro, com idade entre 18 e 34 anos. A maior parte desses usuários (91\%) apresentavam até 3 fotos em seu perfil, com uma grande preferência para o formato de selfies, fotos ao ar livre ou fotos sem camisa. Outros dados coletados nesta etapa foram: 64\% possuíam um texto de descrição, em sua maior parte falando sobre si, $66 \%$ divulgavam seu local de trabalho ou estudo e a grande maioria (em torno de $80 \%$ ) não vinculava outras contas em redes sociais ou programas, como Instagram e Spotify, ao seu perfil no Tinder.

Após a observação, realizei entrevistas semiestruturadas com oito usuárias do programa. O processo de escolha de tais informantes se deu através do procedimento "bola de neve": a partir da minha própria rede de contatos, recebi indicações de mulheres que utilizavam o Tinder e estariam dispostas a contribuir com a pesquisa. O critério de escolha de tais usuárias levou em consideração alguns dos filtros aplicados anteriormente na observação participante realizada na plataforma: mulheres entre 18 e 34 anos, residentes do Rio de Janeiro e que tivessem utilizado o Tinder em seu cotidiano. Ao final de cada entrevista, pedia a cada informante que indicasse uma nova pessoa para participar da pesquisa e, conforme as respostas foram se repetindo, se deu por encerrado o processo de seleção.

Com base na pesquisa empírica, percebeu-se algumas questões importantes na performance de si no Tinder: 1) a preocupação com a autenticidade, tanto no sentido de uma originalidade na criação do perfil, quanto em relação à honestidade das informações ali expostas (tal cenário influencia a construção de uma narrativa de si feita no limiar entre uma auto-promoção e um perfil autêntico); 2) a busca a partir de estereótipos, em um contexto onde são poucas as pistas sociais que permitem avaliar o outro no momento da interação; 3) a apresentação de si a partir do gerenciamento da impressão que se deseja 
transmitir, trazendo a percepção de que o self ali exposto será ou não confirmado em um segundo momento, e trazendo ainda a busca por vestígios e rupturas de tais apresentações em outros contextos online, como outros sites e aplicativos de redes sociais.

\section{Honestidade, auto-promoção e estereótipos}

A partir das respostas obtidas, um dos principais aspectos que as mulheres entrevistadas buscam nos perfis é a autenticidade. Conforme exposto também no trabalho de Ranzini et al. (2016), os selfs se apresentam nas plataformas de relacionamento online seguindo um ideal no limite entre a autenticidade e a auto-promoção. As entrevistadas para este trabalho, quando percebiam um exagero nesta auto-promoção, não iniciavam contato com o perfil correspondente. A autenticidade é apreciada pelas mesmas tanto no sentido de ser honesto com aquilo que se apresenta, como também em se apresentar de forma interessante e original a partir da narrativa de si. Tal percepção e definição configuram uma categoria nativa, ou seja, uma categorização e explicação definidas pelas próprias entrevistadas para este trabalho. Conforme as respostas de Gabriela e Thaysa (nomes fictícios), respectivamente:

Gabriela: Eu acho péssimo, porque muitos homens, acho que sei lá, a maioria tenta mostrar que é muito aventureiro no Tinder e eu acho isso um saco. Aí tem uma foto na trilha e lá no alto da trilha tem a pessoa, de costas, e não dá pra ver a cara. Aí tem uma foto surfando, com a água na cara, e não dá pra ver a cara. Uma foto escalando de costas que só dá pra ver a pedra. Então eu acho que, pra mim, isso não é satisfatório.

Thaysa: Então, assim, se o cara é muito ostentação, tem muita foto de carro ou de moto, de academia, de cultura ao corpo, essas coisas assim, eu já sei que ele não serve pra mim e já tchau! (...) Tem um fator que eu acho interessante, que é um único critério que chama a minha atenção positivamente: caras que falam que tem filhos já na descrição eu acho interessante. Eu já gosto do cara pelo grau de honestidade.

Os dois exemplos de respostas mostram alguns fatores que se repetiram em outras entrevistas: 1) a preocupação em identificar o outro, em um espaço onde as pistas sociais são escassas e é preciso tomar, naquele momento, uma decisão sobre determinado perfil; 2) a aparição de perfís com exageros, no que diz respeito à 
performance de si, e a repulsa por tais perfis; 3) o valor dado à honestidade e aos perfis que realmente se mostram na plataforma, expondo algumas partes de si e realizando, em parte, o processo de self-disclosure no ambiente online.

$\mathrm{O}$ valor dado à honestidade se baseia, de acordo com as informantes, naquilo que o outro usuário possa utilizar a partir dos recursos que o Tinder oferece. Isso se liga à ideia de uma conformidade entre a forma como o usuário se apresenta no aplicativo e a forma como ele irá se apresentar também em outros contextos, principalmente no ambiente offline. Beatriz Polivanov (2014) ao abordar os possíveis desencaixes entre o self online e offline mostra, a partir de sua pesquisa empírica e do estudo de caso do Facebook, que a tendência é que, mesmo com a possibilidade de criar novas narrativas para si, a maioria dos usuários de tal rede social se mantem fiel àquilo que também são fora daquele contexto.

Polivanov (2014) identifica ainda alguns tipos de performances de si nos sites de redes sociais, classificando as mesmas como: autênticas, ou seja, aquelas em que o próprio sujeito entende como sendo uma representação verdadeira de si; os perfis de personagens, indicando apresentações nas quais os usuários intencionalmente criam uma versão exagerada de si, mas que ainda remetem tal construção ao seu próprio self; e os perfís falsos, ou seja, versões nas quais "são utilizados nomes e fotos ou fictícios ou de outras pessoas, não permitindo que seja(m) reconhecido(s) o(s) administrador(es) do perfil" (POLIVANOV, 2014, p. 8).

Nesta pesquisa, percebe-se tal preocupação em identificar o perfil autêntico, aquele que representa uma versão o mais fiel possível com o que cada sujeito entende como sendo o verdadeiro self. Assim, valoriza-se tal construção, pois ela representa para as informantes uma sensação de segurança em iniciar o contato. Além disso, nesta etapa, também já acontece uma triagem e perfis que não correspondem com a busca são evitados de forma mais rápida e eficaz. Tais aspectos podem ser encontrados nas respostas a seguir:

Lorena: Acho que um perfil ideal no Tinder é a pessoa que demonstra a sua vida profissional de forma aberta e honesta. De verdade, né? Diga sua idade real também. Poste fotos sem querer tirar onda, nem ficar se mostrando. Umas fotos normais, decentes.. Não ficar escrevendo coisas que ele não é. 
Marina: Cara, eu acho que um perfil ideal seria: a pessoa tem que condizer com as fotos que ela coloca, né. (...) Então quando eu converso com um cara eu imagino que o perfil dele é ideal pra mim, porque eu acredito, pelo que ele tá dizendo lá, que as fotos dele condizem com o que ele é fora dali. Isso pra mim se torna como um perfil ideal, assim.

Olívia: Em relação às fotos, que obviamente sejam fotos da pessoa, com boa resolução, idealmente sem amigos ou sem óculos escuros, sorrindo. Bom ter um perfil variado de cenários e situações também. [Pesquisadora: E um perfil não satisfatório?] Quando as fotos são muito pixeladas ou só tem foto em grupo ou mesmo só do cara de óculos e você não consegue de fato vê-lo.

Outro aspecto recorrente nos aplicativos é o fato de alguns usuários não utilizarem os recursos da plataforma para realizar uma exposição de si mesmo. Esse fator foi também encontrado na etapa de observação participante, na qual notou-se que há uma grande quantidade de perfis com poucas informações, muitos sem utilizar o recurso da escrita e utilizando apenas duas ou três fotos. As usuárias entrevistadas, por mais que desejassem ver o máximo possível de informações sobre o outro, compreendiam tais perfis com pouca informação como uma dificuldade que o correspondente poderia encontrar na hora de se autoapresentar, já que as mesmas também compartilhavam de tal dificuldade. Além disso, muitas respostas mostravam que as informantes possuíam a noção de que o Tinder é apenas uma primeira impressão que irá se delinear sobre o outro, fazendo com que, apenas a partir da conversa e do encontro, se pudesse confrontar tal impressão com o que de fato a pessoa corresponde, validando ou não a performance do outro.

Ainda sobre a autenticidade em tais aplicativos, Galindo (2014) trabalha com o conceito de autenticidade performada, ou seja, a maneira como performatizamos uma apresentação de nós mesmos, principalmente nos sites de redes sociais, e trabalhamos a noção de autêntico a partir do compartilhamento de narrativas de si que aparentem ser o mais naturais possíveis. Assim, criamos um personagem para retratar nossa realidade a partir daquilo que acreditamos ser nosso verdadeiro self - ou, ao menos, o self através do qual gostaríamos de nos ver retratados, criando um conflito entre o que seria falso ou verdadeiro.

Apesar desse conflito, Galindo resolve tal questão ao compreender que a performance trata-se da criação de um personagem "real", construído a partir de DOI: http://dx.doi.org/ 10.14393/par-v4n1-2019- 51855 Paradoxos, Uberlândia, v. 4, n. 1, p. 83-102, jan./jun. 2019 
uma audiência e dos recursos e limitações de determinado contexto onde ocorre a interação social. Em sua tese sobre o "show do eu", Paula Sibilia (2016, p. 249) afirma que tais fronteiras entre a ficcionalização e a realidade se veem borradas, já que há uma tendência em perfomatizarmos no nosso cotidiano a partir das linguagens midiáticas. Assim, a autora segue sua argumentação afirmando que hoje, a partir dos blogs e sites de redes sociais, "qualquer um" no sentido de ninguém extraordinário (p. 302) - pode ter acesso a ferramentas de criação de si e construir narrativas que serão efetivamente vistas por uma audiência considerável. Isso gera a espetacularização da banalidade da vida cotidiana, nas palavras da autora, e uma preocupação em se mostrar em sua versão autêntica e bem editada.

Assim, de novo, vê-se a construção do self no Tinder nesse limite entre o ser autêntico e o de realizar uma promoção de si mesmo em busca da atração do olhar alheio. Por isso, cabe ressaltar que a performance, muito embora buscando gerenciar a impressão que o outro terá de si, é também o próprio self em si, já que ela será o resultado da autoapresentação e da narrativa de fato recebida e impressa no outro. Nas palavras de Goffman: "em nossa sociedade, o personagem que alguém representa e o próprio indivíduo são, de certa forma, equiparados, e este indivíduo-personagem é geralmente considerado como algo alojado no corpo do possuidor" (2002, p. 231). Assim, o autor enxerga a personalidade encenada como "uma espécie de imagem, geralmente digna de crédito" (idem) e, assim, durante a apresentação de si, o interesse estará em saber se tal performance será ou não acreditada.

Neste contexto, as fotos, parte de tal apresentação, vão apresentar um papel importante na resposta que se deseja obter no Tinder e na performance estabelecida no programa. Conforme apontam algumas das repostas obtidas durante as entrevistas, a primeira foto de cada sujeito, que é a primeira informação sobre o outro com a qual o usuário se depara na plataforma, já interfere na decisão final que será tomada sobre aquele perfil. Se essa primeira foto já apresenta alguma característica ou estereótipo com o qual o correspondente não se identifica, o contato não segue adiante. Como aponta Goffman (2002), no momento da interação social os sujeitos se baseiam em 
“estereótipos não comprovados" (GOFFMAN, 2002, p. 11) para obter uma sensação de segurança durante tal interação. Tais estereótipos irão delinear as possíveis respostas que se deseja obter do outro e o que pode-se ou não esperar.

No Tinder, observa-se que a ausência de algumas pistas sociais, conforme Baym (2010) aponta como um dos aspectos que trazem a segurança na hora da interação online, faz com que os indivíduos se baseiem cada vez mais em estereótipos, conforme relatado nas respostas abaixo.

Gabriela: Essas fotos em festas, bebendo em tal, me passam sim uma impressão ruim. O que é uma hipocrisia da minha parte, porque eu também bebo, também vou em festa e tal, saio com meus amigos. Mas, o Tinder é uma vitrine né? A pessoa não te conhece direito e, enquanto ela não te conhecer e não conversar com você, ela não vai te conhecer realmente. (...) todo mundo bebe, todo mundo sai, mas se num espaço limitado a imagem que você escolhe passar de primeira é uma imagem que você tá na festa, bebendo e tal, me passa uma impressão de que a pessoa é meio fanfarrona, que ela só quer "zoação". E tudo bem, não tem problema.

Olívia: Acho complicado [fotos sem camisa]... Eu não gosto muito dessa vibe egotrip, mas é o Tinder, né? Como um amigo diz: é quase um açougue. (risos) É natural que haja fotos neste sentido. Acho que prefiro algo mais sutil, uma foto de longe, mas não de biquini ou sunga dizendo "olha como sou gostoso". Inclusive, tenho muita preguiça dessa vibe Crossfit. Se tem, já acabo não querendo a pessoa mesmo. É um pouco de preconceito, talvez . Mas é porque são raras as vezes que a pessoa que faz Crossfit não é completamente obcecada com o físico. (Tô respondendo me sentindo mal com algumas respostas, mas no Tinder a verdade é que você parte de um monte de pré-julgamentos que fazem ou não sentido).

As usuárias, portanto, possuem a consciência de estarem partindo de estereótipos não comprovados para analisar os perfis de seus correspondentes, e entendem que tal estratégia é uma das formas de estabelecerem ligações no programa - seja pela falta de outras pistas sociais que poderiam ajudar na identificação do outro ou pelo processo comunicacional, que parte, em certos momentos, de estereótipos. Entre as respostas, também comprova-se outro aspecto importante no que diz respeito ao Tinder: a percepção de que ali é um espaço de exposição regulada do próprio self. A partir de expressões como "vitrine" e "açougue", nota-se que as usuárias percebem que a apresentação de si no Tinder segue a perspectiva de uma impressão, em parte, gerenciada pelo outro, e que tal apresentação busca a aprovação do olhar alheio. 
Além disso, tal configuração mostra também o quanto a "identidade é formada na interação entre o eu e a sociedade" (HALL, 2006, p. 11), seja com o contexto social e cultural ao seu redor, ou no momento da interação com outro indivíduo. Esse segundo aspecto se caracteriza como a alo-definição (MATUCK; MEUCCI, 2005), ou seja, a forma como é percebida tal apresentação de si pelos outros e também a forma como os meios pelos quais se dá tal apresentação acaba restringindo tal narrativa de si. Se pensarmos no Tinder, a alo-definição é formada pela percepção do público sobre determinado perfil e pelas ferramentas que o próprio aplicativo dispõe para a construção do self.

Dessa forma, a impressão que o outro tenta registrar nem sempre segue aquilo que foi planejado, já que a identidade se configura no momento da interação. Novamente, o que surge nas respostas é a preocupação com uma autenticidade e honestidade no que diz respeito ao self que se constrói no aplicativo. As informantes mostram que exageros no que diz respeito à autoapresentação ali disposta geram uma impressão diferente da prevista e, consequentemente, a rejeição.

Carla: E pra mim as fotos dizem aquilo que você quer que os outros vejam. Então se o cara põe lá cinco fotos na academia mostrando o tanquinho dele, ele tá me dizendo que a vida dele é isso. (...) Então, tem umas fotos que você tá vendo que as pessoas tão querendo passar uma imagem que não é, por exemplo, essas fotos de beijando golfinho, beijando a vó... Tá bom, você tá vendo que ele quer dizer que é um bom rapaz. Então, você vai escolher qual a primeira foto que quer botar. O cara que põe cinco fotos de óculos escuros, sabe? O cara não tá se mostrando. Quem não bota foto do rosto, eu nem considero.

Marina: Eu acho meio apelativo quando o cara bota foto com a mãe, foto com cachorro. Eu acho que ele tá apelando pra menina achar "olha só como ele é família, olha como ele é pai de cachorro". Isso me cansa um pouco. Acho que ele pode colocar na descrição que ama o cachorro e ama a mãe. (risos) Ou não bota que ama a mãe! Mas, às vezes, dizer que ama o cachorro, que tem um cachorro, seja importante pra ele. Mas a foto em si eu acho meio apelativo.

As respostas mostram que há a noção, entre as entrevistadas, de uma tentativa entre os correspondentes de imprimir determinada impressão sobre si mesmo. Quando identificam tal tentativa, as informantes desconfiam de tal perfil, no que diz respeito à autenticidade, e acabam caindo, novamente, em “estereótipos não comprovados" (GOFFMAN, 2002) para estabelecer a ponte 
entre a apresentação recebida e a impressão de fato gerada em tais usuárias. Assim, o que as informantes buscam nos perfis é uma imagem não exagerada de si mesmo, que represente o cotidiano do outro usuário e que não caia em repetições de narrativas identitárias já formatadas. Esses aspectos exibem alguns dos conflitos existentes no cenário de como é dado o processo de subjetivação na pós-modernidade. Apesar de maior liberdade na hora da construção do self e uma possibilidade em recriar a própria narrativa de si, por vezes os indivíduos caem em estilos de vida e estratégias identitárias já pré-formatadas.

\section{Gerenciamento da impressão e polimídia}

Para finalizar, serão discutidos os conceitos de polimídia, audiência imaginada e colapso de contexto, ligados às performances no Tinder. Daniel Miller e Mirca Madianou (2012) lançaram a ideia de polimídia como um ambiente de "oportunidades comunicacionais que funciona como uma estrutura integrada" (p. 170), no qual cada mídia passa a ser definida a partir de termos relacionais com outras mídias no contexto geral. Assim, cada indivíduo buscaria oportunidades comunicacionais distintas a partir da possibilidade de acesso a diferentes tipos midiáticos que possui à disposição. O que os autores ressaltam é que a escolha entre diferentes mídias recai não só em suas especificidades técnicas, mas também em seu contexto social e emocional. Assim, escolher utilizar o Whatsapp em detrimento do Messenger, por exemplo, pode indicar não só uma preferência pelas especificidades técnicas do primeiro, mas deve ser analisado em um contexto maior e social, envolvendo os significados simbólicos para diferentes grupos sociais.

No que tange à credibilidade, o contexto de polimídia ajuda a criar tal sensação, ao possibilitar a confirmação de determinado perfil nas diversas redes digitais. Assim, um usuário pode buscar outro que conheceu no Tinder em diferentes ambientes online, e confirmar fatos que viu na primeira plataforma para se sentir mais seguro em relação à identidade apresentada e iniciar o contato. A vinculação de outras contas ao Tinder é uma parte importante para a disponibilidade de pistas sociais na hora da construção identitária em ambientes digitais. Sem a 
presença física, o vínculo e publicação de informações de outro gênero ajudam a criar uma sensação de credibilidade e confiança de que aquele perfil corresponde verdadeiramente àquela pessoa. $\mathrm{O}$ próprio fato do aplicativo estar conectado à conta no Facebook é uma estratégia por parte da empresa desenvolvedora de evitar perfis falsos na plataforma. Assim, conectar a conta de outro aplicativo ou oferecer cada vez mais informações ao perfil facilita o início de uma interação.

Nesse contexto, cabe ressaltar também que é esperado que haja diferentes comportamentos em diferentes espaços digitais de interação. Há estratégias de autoapresentação e de interação diferentes a depender da audiência imaginada (LITT; HARGITTAI, 2016), ou seja, do público com o qual se imagina estar correspondendo através daquela plataforma. Esse público corresponde a "uma audiência heterogênea composta por elementos com diferentes vivências e perspectivas do que poderá ser socialmente correto ou expetável" (SEPÚLVEDA, 2016, p. 12-13). Esse aspecto apareceu em algumas respostas durante as entrevistas:

Marina: Quando eu gosto da pessoa e a conversa tá ok, eu procuro sim. Não sei se todo mundo deveria fazer, mas é uma boa estratégia. Porque aí você vê além do que tá ali no aplicativo. E sim, já tive surpresa. Tem gente que já coloca no perfil [do Tinder] "Bolsonaro 2018", mas tem a pessoa que não coloca. Daí a pessoa acaba colocando no Facebook essa visão política. Pra mim, facilita, porque aí já parei de conversar por conta disso.

Paula: Já tive informações políticas que a pessoa não compartilhou no Tinder, a gente não conversou sobre, mas eu acabei descobrindo no Facebook. Era tipo nada a ver comigo, "bolsominion". E aí eu já deixei a conversa morrer e tal.

Thaysa: Eu procuro depois do match, se a gente já tiver conversando, antes não. Porque eu acho que é meio que roubar no jogo e já saber a carta que a pessoa tem na mão. Eu prefiro conhecer a pessoa com aquilo que ela tá me apresentando.

Essa perspectiva pode gerar o chamado "colapso de contextos", que "ocorre quando as pessoas são forçadas a lidar simultaneamente com contextos sociais de outra forma não relacionados que estão enraizadas em diferentes normas e aparentemente exigem diferentes respostas sociais" (boyd apud SEPÚLVEDA, 2016, p. 13). Muitas vezes, adequa-se o conteúdo a partir da audiência imaginada e do contexto em que acontece tal interação. Assim, apesar 
da apresentação de informações em contextos digitais seguir a lógica de audiência imaginada, há algumas rupturas que acontecem e que geram tal efeito de colapso.

Além do referido colapso nos ambientes digitais, há também a questão das rupturas entre aquilo que se apresenta online para aquilo que é apresentado offline, conforme já apontado anteriormente pela exposição do trabalho de Polivanov (2014), que trata o conceito de performance como "uma construção discursiva performatizada, dirigida para uma audiência (imaginada)" (p. 2). Para a autora, mesmo que buscando a autenticidade e a fidelidade àquilo que a persona acredita ser seu verdadeiro self, nas redes sociais digitais veríamos sempre uma versão performatizada da identidade de cada usuário. Assim, os perfis podem sofrer desencaixes daquilo que apresentam online e aquilo que apresentam offline, não necessariamente por representar uma abordagem completamente falsa da própria identidade, mas pela noção de que é possível transparecer apenas parte da mesma e de que os selves podem ser moldados para atender as expectativas de audiências específicas de cada contexto.

\section{Conclusão}

A forma como cada indivíduo enxerga a própria identidade sofre inúmeras interferências e variações. Uma delas é o próprio momento histórico e social no qual o sujeito está inserido. A pós-modernidade trouxe novas interpretações para o entendimento da identidade, como a maior percepção do self como algo que não é dado desde o nascimento, mas uma construção em processo durante toda a trajetória do indivíduo. Assim, entende-se que o self possa adquirir inúmeras formas, e que a identidade está sujeita a contradições e diferentes nuances.

Uma delas é o próprio contexto e ambiente no qual cada um está no momento da interação social. Em A Representação do Eu na Vida Cotidiana (2002), Goffman mostra que as representações de si se constroem a partir da ideia de uma performance e a partir da noção de que, com tal autoapresentação, é possível de alguma forma gerenciar a impressão que o outro terá de nós. Isso representa o quanto as construções identitárias são, em parte, construídas a partir de um objetivo e pelo fato de que os indivíduos buscam uma segurança na hora da 
interação social, já que gerenciar a impressão que o outro terá pode permitir saber de antemão a forma como será tratado e algumas das respostas que irá receber.

Da mesma forma, a maneira como essa construção identitária será interpretada e recebida também sofre influências externas à própria percepção do público. Seja pelo fato desse público também estar inserido em um cenário, ou pelo fato da própria tensão entre a tentativa de gerenciamento da impressão do autor e a bagagem que o público carrega de experiências anteriores, sociais e culturais. Neste trabalho, foi possível notar que a percepção que as mulheres entrevistadas possuíam acerca das narrativas de autoapresentação dos homens é composta por uma série de fatores sociais e políticos, e, entre eles, a própria dinâmica e ferramentas que o Tinder oferece.

O aplicativo não fornece muitas opções para que seus usuários construam suas narrativas de si. Com isso, são poucas as pistas sociais que os indivíduos possuem sobre o correspondente, fazendo com que eles tenham a noção de que aquilo que veem na plataforma é apenas uma primeira impressão do outro impressão essa que será ou não confirmada em um segundo momento. Além disso, há também a percepção de que tal impressão é apenas aquela parte que o outro "permite" e deseja que seu público veja, o que faz com que os usuários fiquem atentos a outros vestígios, inclusive com a busca em outras esferas e contextos, que possam fornecer um número maior de informação.

Essa busca se encaixa em um contexto no qual espera-se evitar riscos, refinar os filtros e encontrar um correspondente que se encaixe o mais próximo possível do que se imagina como ideal. Nesse cenário, há ainda a noção de que o Tinder fornece poucas opções de filtragens em suas próprias ferramentas, o que dificulta o refinamento da busca. Isso gera um contexto no qual os usuários buscam seus próprios mecanismos na hora de aplicar filtros ao programa; seja a partir da construção do próprio perfil, com a exposição de textos e imagens que mostrem um estilo de vida específico, na esperança de encontrar um correspondente que compartilhe de tal estilo, ou ainda a partir do embasamento em estereótipos não comprovados na hora de visualizar e interpretar os perfis vistos no programa.

Sobre a primeira opção, a partir de trabalhos anteriores e da parte empírica deste trabalho, nota-se que a construção do próprio perfil é feita de forma 
estratégica, em um limiar entre corresponder aquilo que se acredita ser o verdadeiro self e uma autopromoção. Essa promoção de si mesmo vai delinear não só a busca pelo match, já que os perfis na plataforma são julgados pelo olhar alheio e pela aprovação, mas também em conseguir que esse match venha estrategicamente do público com o qual se deseja corresponder, na tentativa da aplicação de um filtro mais restrito no uso do programa.

Já a segunda perspectiva diz respeito exatamente à outra etapa de utilização do programa: o momento no qual os usuários analisam os perfis dos possíveis correspondentes e precisam tomar, neste momento, uma decisão sobre cada perfil. Isso gera um caráter de urgência na utilização da plataforma, além de uma vontade permanente em sempre querer ver o próximo da lista.

Isso mostra que o programa pode engendrar formas de uso e consumo nos seus usuários, transferindo dinâmicas próprias e transformando as experiências do utilizador no programa. A partir disso, uma das explicações para o forte embasamento em estereótipos na hora da avaliação dos perfis pode estar relacionado à própria dinâmica do programa, que disponibiliza poucas pistas sociais sobre o outro usuário e pressupõe uma resposta imediata.

Outro aspecto buscado na hora da avaliação dos perfis é a autenticidade, tanto no sentido de uma busca por perfis honestos quanto por perfis originais. A questão da honestidade foi tratada a partir da percepção de um perfil que não exagerasse na auto-promoção de si no programa, e relatasse uma versão de si o mais verdadeira possível, na perspectiva de não sofrer rupturas em outros contextos, como o contexto offline. Entende-se que o termo "honestidade" corresponde a nuances muito mais complexas, pois, conforme tratado em vários pontos deste trabalho, a performance de si não é necessariamente uma versão falsa de si mesmo, mas pode corresponder a apenas uma parte do self-aquela que se deseja ser vista.

Em um contexto de múltiplas escolhas a todo o momento, busca-se aquilo que se encaixa de forma mais perfeita possível nos parâmetros estabelecidos para a procura, evitando possíveis tensões e surpresas negativas no futuro. Isso se liga tanto ao caráter calculista das relações e construção identitária como ao modo como o consumo influencia tais relações, mesmo que indiretamente (BAUMAN, 2004). Durante algumas entrevistas, inclusive, surgiram expressões como 
"vitrine", "açougue" e o verbo "vender", acentuando o caráter de escolhas e a ligação com a forma como o consumo influencia as relações.

Apesar disso, acredita-se que o Tinder não seja o causador direto dessa lógica, pois é algo que vai além do aplicativo e está ligado à dinâmica da sociedade de consumo - com ou sem o aplicativo, o consumo se espalha por diversas áreas de nossas vidas e influencia também relações e afetos. De certa forma, é possível afirmar que o Tinder torna as relações mais voláteis, na medida em que, se um contato não deu certo, o programa oferece uma lista infinita de possíveis novas conexões e parceiros em potencial. Porém, da mesma forma, tal visão não é algo tão simplificado, pois, conforme recorrente em algumas entrevistas, quando um contato não preenche as expectativas e não segue adiante irá gerar uma frustração. Algumas informantes narraram suas decepções no programa, o que as levou, em certo momento, a desinstalar o aplicativo do celular e permanecer um tempo sem usá-lo antes de voltar e recomeçar do zero.

Assim, é possível perceber o quanto o Tinder funciona como uma ferramenta para algo que a sociedade de certa forma já pratica. Alguns dos trabalhos analisados nesta pesquisa abordam o quanto o Tinder pode influenciar as relações e, algo recorrente encontrado nos dados empíricos, é a percepção de que o aplicativo não difere tanto assim de outros ambientes de interação.

\section{Referências}

BAUMAN, Zygmunt. Amor líquido: Sobre a fragilidade dos laços humanos. Rio de Janeiro: Jorge Zahar, 2004.

BAYM, Nancy. Personal Connections in the Digital Age. Malden: Polity Press, 2010.

CARRERA, Fernanda. Gerenciamento de impressões, música e sites de redes sociais: o self a partir do compartilhamento de letras e vídeos. Contemporânea, vol.10, n.01, janeiro-abril de 2012.

FRAGOSO, Suely; RECUERO, Raquel; AMARAL, Adriana. Métodos de pesquisa para internet. Porto Alegre: Editora Sulina, 2012. 
GALINDO, Manuela. Do self ao selfie: o autorretrato digital e a subjetividade contemporânea. Dissertação (Mestrado em Comunicação) - Universidade Federal Fluminense, Instituto de Arte e Comunicação Social, 2014.

GIDDENS, Anthony. Modernidade e identidade. Rio de Janeiro: Jorge Zahar Editor, 2002.

GOFFMAN, Erving. A representação do eu na vida cotidiana. Petrópolis: Vozes, 2009.

HALL, Stuart. A identidade cultural na pós-modernidade. Rio de Janeiro: DP\&A, 2006.

HINE, Christine. "Estratégias para etnografia da internet em estudos de mídia". In: CAMPANELLA, Bruno; BARROS, Carla. Etnografia e consumo midiático: novas tendências e desafios metodológicos. Rio de Janeiro: E-papers, 2016.

LITT, Eden, HARGITTAI, Eszter. The Imagined Audience on Social Network Sites. In: Social Media + Society, SAGE, 2016. https://doi.org/10.1177/2056305116633482.

MADIANOU, Mirca; MILLER, Daniel. Polymedia: Towards a new theory of digital media in interpersonal communication. In: International Journal of $\begin{array}{lllll}\text { Cultural } & \text { Studies, } & \text { vol. } & 16, & \text { n.02, }\end{array}$ https://doi.org/10.1177/1367877912452486.

MATUCK, Artur; MEUCCI, Arthur. A criação de identidades virtuais através das linguagens digitais. In: Comunicação, mídia e consumo, São Paulo, v. 2, n. 4, p. 157-182, 2005.

POLIVANOV, Beatriz. Dinâmicas identitárias em sites de redes sociais - Estudo com participantes de cenas de música eletrônica no Facebook. Multifoco: Rio de Janeiro, 2014.

. Personas no Facebook: Percepções sobre (Des)encaixes entre Selves On e Offline. In: Congresso Internacional Comunicação e Consumo, 2014. Anais... São Paulo: Comunicon, 2014. https://doi.org/10.11606/issn.22382593.organicom.2015.139280.

RANZINI, Giulia; LUTZ, Christoph; GOUDERJAAN, Marjolein. Swipe Right: An Exploration of Self-Presentation and Impression Management on Tinder. In: 66th Annual Conference of the International Communication Association (ICA), 2016, Fukuoka, JP.

RECUERO, Raquel. Redes Sociais na Internet. Porto Alegre: Sulina, 2009. 
RIBEIRO, José Carlos; FALCÃO, Thiago; SILVA, Tarcízio. Gerenciamento de Impressões Pessoais através de Aplicativos Sociais: Uma Proposta de Análise. In: XXXIII Congresso Brasileiro de Ciências da Comunicação - INTERCOM, 2010. Caxias do Sul. Anais... São Paulo: INTERCOM, 2010. https://doi.org/10.1590/1809-5844201619.

SÁ, Simone Pereira de; POLIVANOV, Beatriz. Auto-reflexividade, coerência expressiva e performance como categorias para análise dos sites de redes sociais. In: Contemporânea. Salvador, v. 10, n. 03, p. 574-596, 2012.

SIBILIA, Paula. O show do eu - A intimidade como espetáculo. Rio de Janeiro: Contraponto, 2016.

SIMMEL, Georg. A metrópole a e vida mental. In: VELHO, Otávio. O fenômeno urbano. Rio de Janeiro: Zahar, 1973.

SLATER, Don. Cultura do consumo e modernidade. São Paulo: Nobel, 2002.

WARD, Janelle. What are you doing on Tinder? Impression management on a matchmaking mobile app. Information, Communication \& Society, novembro de 2016. https://doi.org/10.1080/1369118x.2016.1252412.

Data Recebimento: $31 / 05 / 19$

Data Aprovação: 19/08/19

${ }^{1}$ Dados enviados em entrevista por email com a assessoria do programa Tinder no Brasil.

${ }^{2}$ Parte da corrente do interacionismo simbólico, Goffman analisa os contextos de interação face a face, mas, ao se tratar de ambientes mediados e digitais, é possível realizar uma transposição dos conceitos propostos pelo autor ao que se refere a esse tipo de interação, já que o mesmo trabalha a apresentação do self "como algo que se dava de modo contextualizado, num determinado ambiente e que pressupunha um público passível de ser antecipado e definível” (POLIVANOV, 2014, p. 81). 